Research Paper

\title{
Binase treatment increases interferon sensitivity and apoptosis in SiHa cervical carcinoma cells by downregulating E6 and E7 human papilloma virus oncoproteins
}

\author{
Vladimir A. Mitkevich ${ }^{1, *}$, Ksenia M. Burnysheva ${ }^{1, *}$, Irina Yu Petrushanko ${ }^{1}$, Alexei \\ A. Adzhubei ${ }^{1}$, Alexey A. Schulga ${ }^{2}$, Peter M. Chumakov ${ }^{1}$ and Alexander A. Makarov ${ }^{1}$ \\ ${ }^{1}$ Engelhardt Institute of Molecular Biology, Russian Academy of Sciences, 119991 Moscow, Russia \\ ${ }^{2}$ Shemyakin-Ovchinnikov Institute of Bioorganic Chemistry, Russian Academy of Sciences, 117871 Moscow, Russia \\ "These authors have contributed equally to this work \\ Correspondence to: Vladimir A. Mitkevich, email: mitkevich@gmail.com \\ Alexander A. Makarov, email: aamakarov@eimb.ru \\ Keywords: cytotoxic RNase, HPV, cancer cells, apoptosis, viral oncoproteins \\ Received: March 22, $2017 \quad$ Accepted: July 25, $2017 \quad$ Published: August 10, 2017 \\ Copyright: Mitkevich et al. This is an open-access article distributed under the terms of the Creative Commons Attribution License \\ 3.0 (CC BY 3.0), which permits unrestricted use, distribution, and reproduction in any medium, provided the original author and \\ source are credited.
}

\section{ABSTRACT}

In this study, we determined whether binase, a ribonuclease from Bacillus pumilus, increases interferon sensitivity and apoptosis in SiHa cervical cancer cells infected with high-risk human papilloma virus (HPV) strain 16. Binase treatment increased SiHa cell apoptosis in a time- and concentration-dependent manner, as determined by flow cytometry, WST tests and real time xCelligence cell index analysis. Binase-treated SiHa cells showed reduced expression of E6 and E7 viral oncoproteins and increased expression of their intracellular targets, p53 and pRb. Combined treatment with binase and IFNa2b enhanced the interferon sensitivity of HPV-positive SiHa cells. By contrast, combined treatment with binase and IFNa2b in HPV-negative C33A cervical cancer cells, which do no expess E6 and E7, elicited no changes in interferon sensitivity or $\mathrm{p} 53$ and pRb expression. These findings suggest binase enhances interferon sensitivity and apoptosis in HPV-positive SiHa cervical cancer cells by suppressing E6 and E7 viral protein expression.

\section{INTRODUCTION}

Human papilloma virus (HPV) infection is one of the most common causes of sexually transmitted diseases worldwide. High-risk strains of the virus (HPV-16 and HPV-18) are linked to cancers of the cervix, anus, vulva, vagina, penis, mouth, head and neck in untreated individuals [1]. Majority of cervical cancer cases are HPV related, with $70 \%$ of cases infected with HPV-16 and HPV-18 [2]. More than 90 percent of anal cancers are caused by HPV, especially HPV-16 [3]. About 70 percent of oropharyngeal cancers are caused by HPV, with more than $50 \%$ cases linked to HPV-16 [4].

Mechanisms of malignant transformation of cells by HPV are well understood [5]. To promote virus replication in HPV infected epithelial cells, the E6 and E7 viral proteins interfere with cellular functions like cell division and stress surveillance. These changes result in uncontrolled divisions of the infected cells coupled to their escape from apoptosis. The E7 and E6 viral proteins target and inhibit the tumor suppressor proteins, $\mathrm{pRb}$ and $\mathrm{p} 53$, which results in malignant transformation [6]. In resting cells, the retinoblastoma protein $(\mathrm{pRb})$ prevents unscheduled DNA replication by blocking the E2F transcription factor, which drives transcription of the S-phase genes [6]. The viral E7 protein binds to $\mathrm{pRb}$, thereby releasing E2F. Unscheduled DNA replication elicits p53 pathway in normal cells, which results in apoptosis. To counteract this response, the viral E6 protein directs ubiquitin-mediated proteasome degradation of p53. As a result, HPV infected cells become resistant to 
p53-mediated apoptosis. Besides, HPV-specific proteins interfere with multiple components of the interferon (IFN) signaling pathway to circumvent immune surveillance [7]. IFN therapy is recommended to treat HPV infections since IFN signaling is necessary for anti-viral immunity [7]. Patients with genital warts induced by low-risk HPV types respond well to interferon treatment [5]. But, high-risk HPVs downregulate IFN, which renders IFN therapy ineffective $[6,7]$. However, IFN therapy could be beneficial for HPV-positive cancers if combined with treatments that abrogate the virus-mediated effects and restore IFN signaling. However, treatments that specifically target HPV-mediated effects in cancer cells are currently not available.

Ribonucleases (RNases) are promising tools to cure neoplasia and viral infections [8]. They selectively eliminate various types of cancer cells [9, 10] and suppress replication of a number of viruses [11]. Binase is the RNase from Bacillus pumilus, which is an efficient therapeutic agent against various types of malignant cells $[12,13]$. The toxicity of binase depends on the expression levels of KIT, AML1-ETO, FLT3 and RAS oncogenes in different cell systems [14-16]. For instance, binase treatment decreases KIT oncogenic protein expression, thereby killing Kasumi-1 acute myeloid leukemia cells [14]. Binase does not initiate necrosis in cell cultures and in vivo mouse tumor models, but inhibits tumor growth and metastasis [17]. Besides, binase treatment is not associated with toxicity in mice and promotes liver regeneration in mice bearing Lewis lung carcinoma cells [18]. Binase also demonstrates anti-viral activity against rabies, murrain and influenza viruses $[11,19]$. Therefore, we investigated if binase could potentiate specific cytotoxic effects against $\mathrm{SiHa}$ cervical cancer cells that are transformed by the high risk HPV16 and restore interferon sensitivity in infected cells.

\section{RESULTS}

\section{Binase treatment decreases viability of HPV- positive $\mathrm{SiHa}$ cells}

To test the effects of binase on HPV-positive cervical carcinoma cells, we treated $\mathrm{SiHa}$ cells with different concentrations of binase. The viability of $\mathrm{SiHa}$ cells treated with $0.8,8$ and $32 \mu \mathrm{M}$ binase decreased by 26, 63 and $79 \%$, respectively at $48 \mathrm{~h}$ and 35, 80 and $90 \%$, respectively at $72 \mathrm{~h}$ (Figure $1 \mathrm{~A}$ ). The $\mathrm{IC}_{50}$ of binase at $72 \mathrm{~h}$ (concentration at $50 \%$ cell death) was $1.2 \pm 0.2 \mu \mathrm{M}$ (Supplementary Figure 1). Cell viability correlated with dynamic changes in cell index based on xCELLigence real time cell analysis (Figure 1B, 1C). FACS analysis with AnnexinV/propidium iodide double staining showed that treatment with 0.8 and $8 \mu \mathrm{M}$ binase for $48 \mathrm{~h}$ resulted in $7 \%$ and $18 \%$ apoptotic cells, respectively (Figure $2 \mathrm{~A}$ ) and $11.5 \%$ and $26 \%$ dying cells, respectively (Figure $2 \mathrm{~B}$ ). The fraction of necrotic cells was less than $1 \%$ for all samples treated with binase.

\section{Binase downregulates HPV E6 and E7 proteins in SiHa cells}

We previously showed that the efficacy of binase against cancer cells was dependent on the expression levels of oncogenic proteins such as $c K I T, A M L 1-E T O$, FLT3 and RAS [14-16]. Since the two HPV-16 oncogenes, $E 6$ and $E 7$ determine the transformation status of $\mathrm{SiHa}$ cells, we determined the effects of binase on the levels of E6 and E7 proteins and their host-cell targets p53 and $\mathrm{pRb}$. Intracellular levels of E6 and E7 proteins were significantly decreased at $48 \mathrm{~h}$ after treating SiHa cells with $8 \mu \mathrm{M}$ binase (Figure 3A, 3B). Concurrently, p53 and $\mathrm{pRb}$ levels increased by 1.5 - and 3 -fold, respectively (Figure 3C, 3D). These results demonstrated that binase downregulated E6 and E7 viral proteins, while upregulating the $\mathrm{p} 53$ and $\mathrm{pRb}$ in $\mathrm{SiHa}$ cells.

\section{Binase treatment enhances interferon sensitivity of SiHa cells}

The viral E6 and E7 proteins render HPV-infected cells resistant to treatment with type I IFNs [20]. Since binase treatment suppressed E6 and E7 levels in SiHa cells, we investigated if binase treatment restored interferon response of HPV-positive cells. Incubation of SiHa cells with $1-500 \mathrm{ng} / \mathrm{ml}$ of IFN $\alpha 2 \mathrm{~b}$ alone for $72 \mathrm{~h}$ did not affect viability (Figure 4). But, combined treatment with $0.8 \mu \mathrm{M}$ binase and $1-500 \mathrm{ng} / \mathrm{ml}$ IFN $\alpha 2 \mathrm{~b}$ reduced $\mathrm{SiHa}$ cell viability by $30-90 \%$ (Figure 4 ). Real time analysis of changes in the cell index showed a correlation between increased cell index changes and decreased viability in SiHa cells treated with a combination of binase and IFN $\alpha 2 \mathrm{~b}$ (Figure $5 \mathrm{~A}, 5 \mathrm{~B}$ ). The toxicity of binase was evident at $24 \mathrm{~h}$ and progressed substantially during the next $24 \mathrm{~h}$ (Figure 5A). While treatment of $\mathrm{SiHa}$ cells with $1-100 \mathrm{ng} / \mathrm{ml} \mathrm{IFN \alpha 2b}$ did not affect viability, the combined treatment of binase and IFN $\alpha 2 b$ induced significant apoptosis in a dose-dependent manner (Figure 2). Moreover, treatment with $100 \mathrm{ng} / \mathrm{ml}$ IFN $\alpha 2 \mathrm{~b}$ did not affect expression of E6, E7, p53 and pRb proteins at $48 \mathrm{~h}$ (Figure 3). But, combined treatment with

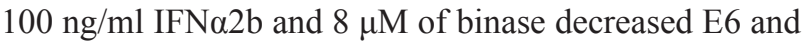
E7 and increased p53 and pRb levels in SiHa cells similar to binase-only treatment (Figure 3).

\section{Binase does not increase interferon sensitivity of HPV-negative C33A cervical carcinoma cells}

To test if the interferon sensitivity of HPV-positive SiHa cells was due to reduced E6 and E7 viral protein levels, we tested the effects of IFN $\alpha 2 \mathrm{~b}$ and binase on HPVnegative cervical carcinoma cells C33A, which do not express $\mathrm{E} 6$ and $\mathrm{E} 7$ proteins. The $\mathrm{IC}_{50}$ for binase $7.6 \pm 3.1 \mu \mathrm{M}$ 

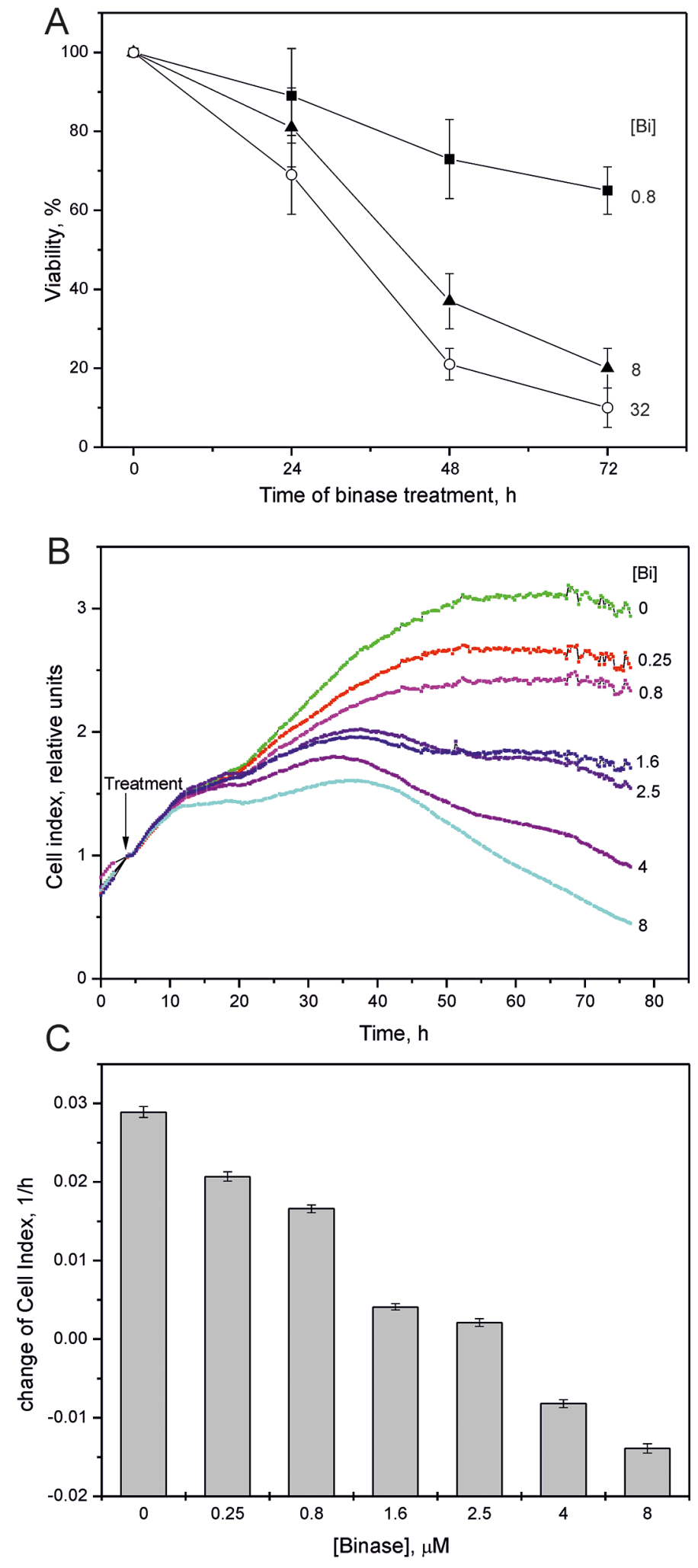

Figure 1: Effect of binase on SiHa cells. (A) WST-1 assay showing percent viability of SiHa cells treated with $0.8,8$ and $32 \mu \mathrm{M}$ binase for 24, 48 and $72 \mathrm{~h}$ relative to control without binase treatment. Data represents mean \pm SD of at least three independent experiments with triplicate samples each. (B) Real-time cell index changes in SiHa cells treated with or without $0.25-8 \mu \mathrm{M}$ binase for $72 \mathrm{~h}$ using xCELLigence real time cell analyser. Arrow indicates the treatment time. Cells were grown in multiple wells of an E16-plate and the values represent average of three measurements. (C) The change in the rate of cell indexes of SiHa cells treated with or without binase in a 4-76 $\mathrm{h}$ time frame are shown. 

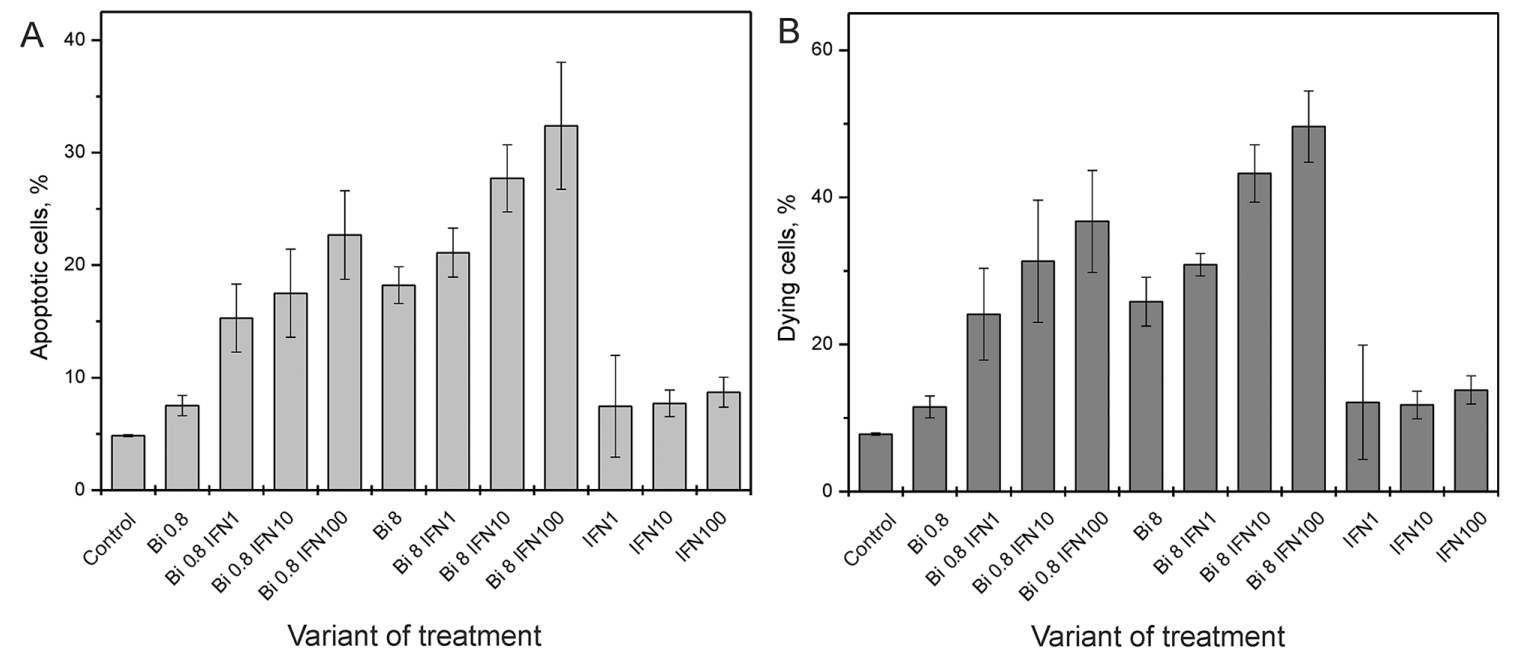

Figure 2: Effect of binase on SiHa cell death. Flow cytometry analysis of (A) apoptotic and (B) dying HPV-positive SiHa cells treated with 0.8 and $8 \mu \mathrm{M}$ binase with or without 1,10 and $100 \mathrm{ng} / \mathrm{ml} \mathrm{INF} \alpha 2 \mathrm{~b}$ at $48 \mathrm{~h}$. The AnnexinV $\mathrm{PI}^{-}$cells were considered apoptotic (lower right quadrant), while AnnexinV $\mathrm{PI}^{+} \mathrm{PI}^{+}$(upper right quadrant), AnnexinV ${ }^{+} \mathrm{PI}^{-}$(lower right quadrant) and $\mathrm{AnnexinV}^{-} \mathrm{PI}^{+}$(upper left quadrant) were considered as dying cells. The values represent mean $\pm \mathrm{SD}$ of at least three independent experiments performed in triplicate.
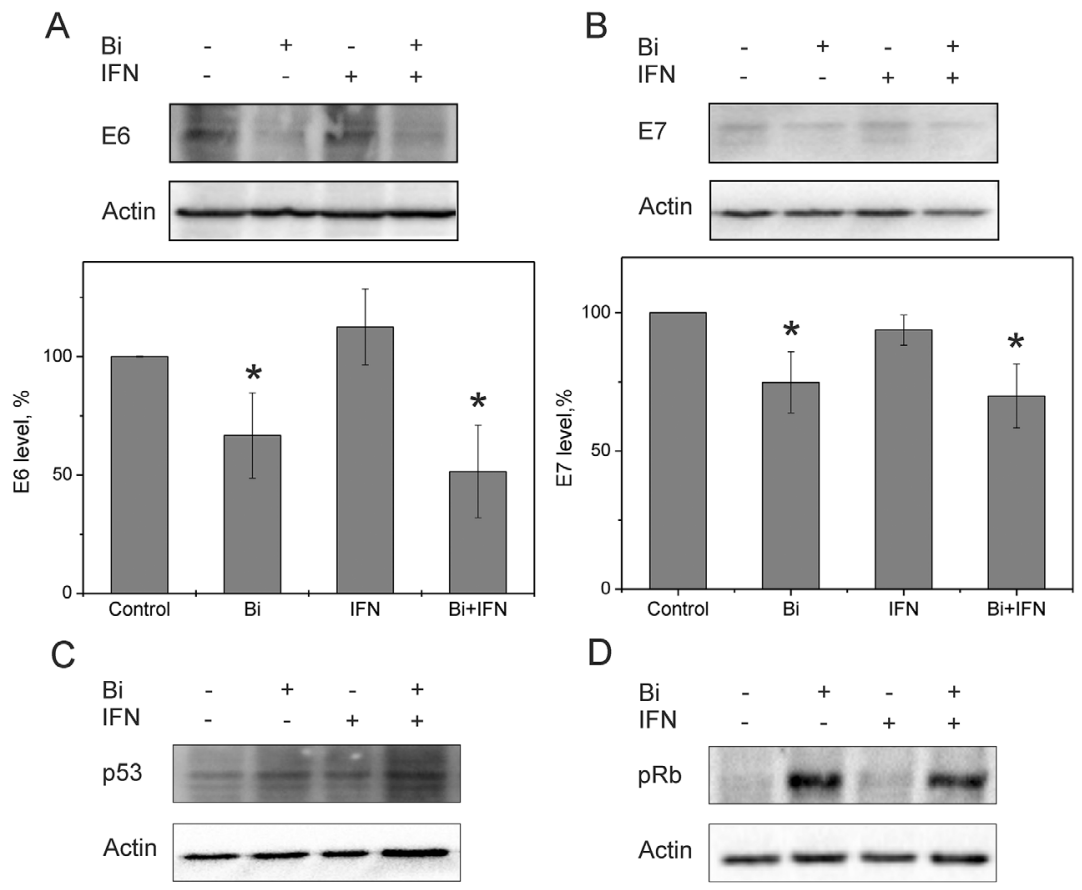

$\mathrm{D}$
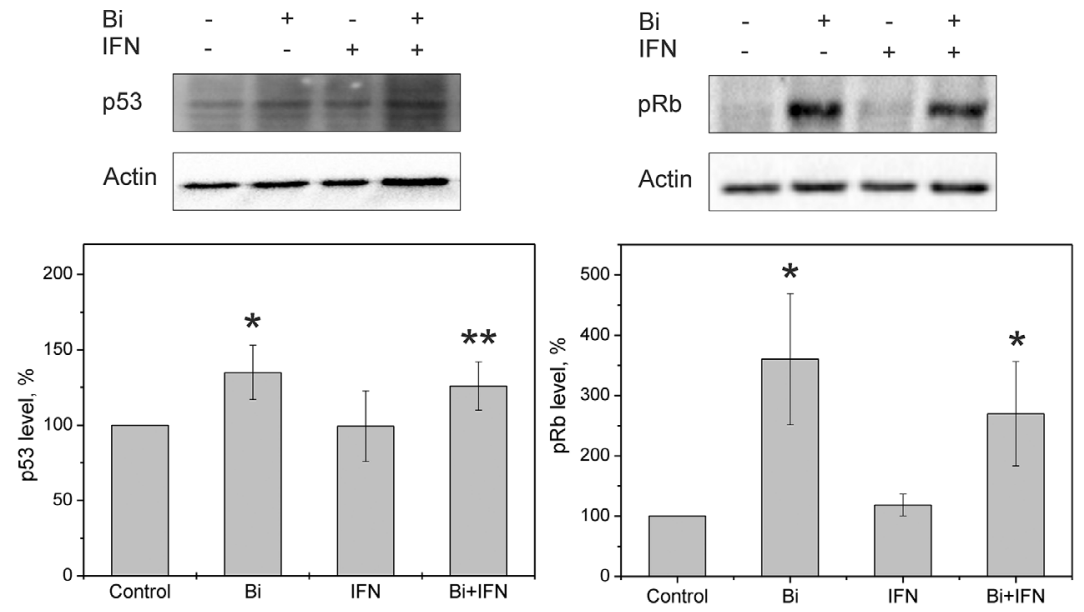

Figure 3: Expression of E6 and E7 HPV oncoproteins and their cellular targets, p53 and pRb in binase treated SiHa cells. Representative western blot and bar graph shows (A) E6 (B) E7 (C) p53 and (D) pRb protein levels in SiHa cells treated with 8 $\mu \mathrm{M}$ binase with or without $100 \mathrm{ng} / \mathrm{ml} \mathrm{INF} \alpha 2 \mathrm{~b}$ for $48 \mathrm{~h}$, relative to untreated control cells. Each bar represents mean $\pm \mathrm{SD}$ value from three independent experiments. Note: * denotes $\mathrm{p}<0.05 ; * *$ denotes $\mathrm{p}=0.07$, compared to control. 

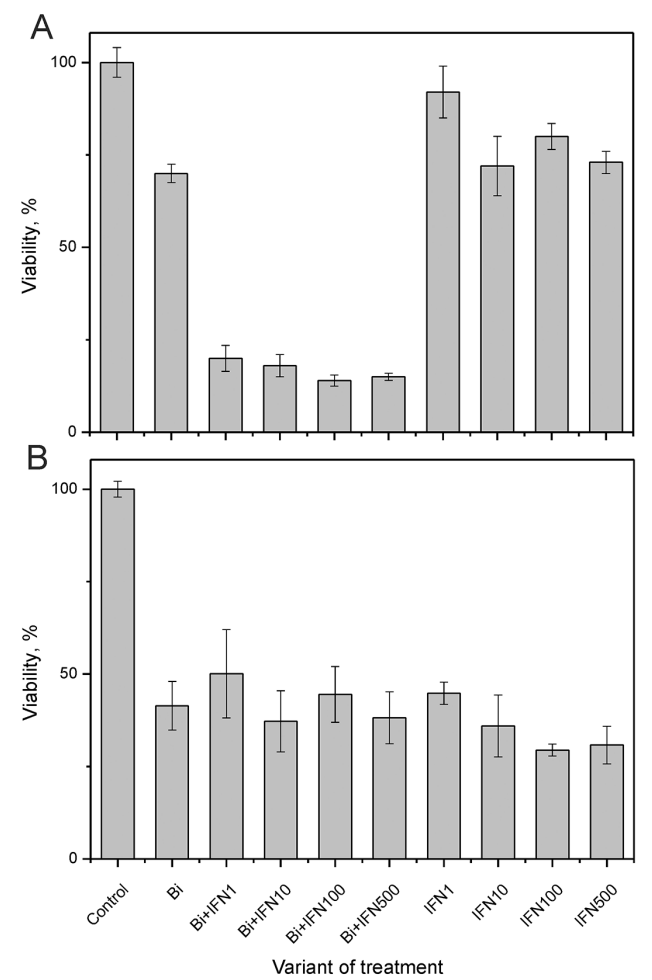

Figure 4: Effect of binase and INFa2b on viability of SiHa and C33A cells. Percent viability of (A) SiHa and (B) C33A cells treated with $0.8 \mu \mathrm{M}$ and $8 \mu \mathrm{M}$ binase, respectively with or without $1,10,100$ and $500 \mathrm{ng} / \mathrm{ml} \mathrm{INF} \alpha 2 \mathrm{~b}$, relative to control without treatment at $72 \mathrm{~h}$. Each value represents mean \pm SD of at least three independent experiments performed in triplicate.
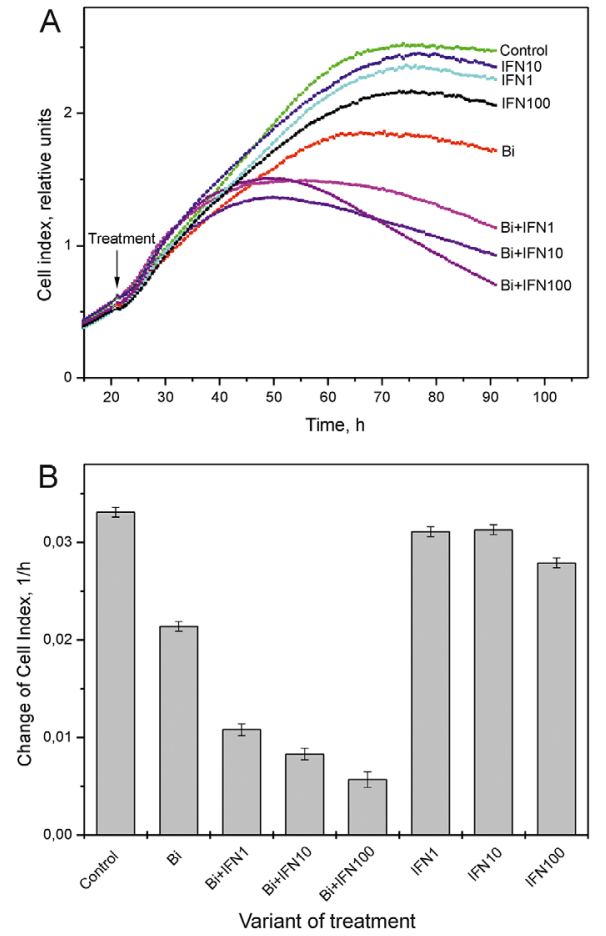

Figure 5: Real time cell index analysis of SiHa cells treated with binase and INFa2b combination. (A) Real-time cell index analysis of SiHa cells treated with $0.8 \mu \mathrm{M}$ binase with or without 1,10 and $100 \mathrm{ng} / \mathrm{ml} \mathrm{INF} \alpha 2 \mathrm{~b}$ for $70 \mathrm{~h}$. Arrow denotes treatment start time. Cells were grown in multiple wells of a E16 plate and the values represent average of three measurements. (B) The change of cell indexes of SiHa cells treated with $0.8 \mu \mathrm{M}$ binase with or without 1,10 and $100 \mathrm{ng} / \mathrm{ml} \mathrm{INF} \alpha 2 \mathrm{~b}$ between $21-91 \mathrm{~h}$ time points. 
for C33A cells at $72 \mathrm{~h}$ (Supplementary Figure 1B), which was lower than that of SiHa cells (Supplementary Figure 1A). The viability of C33A cells was reduced by $59 \%$ at $72 \mathrm{~h}$ after treatment with $8 \mu \mathrm{M}$ binase or combination of 8 $\mu \mathrm{M}$ binase plus $100 \mathrm{ng} / \mathrm{ml}$ IFN $\alpha 2 \mathrm{~b}$ (Figure 4B). Treatment with either binase or a combination of binase and IFN $\alpha 2 b$ did not enhance apoptosis in C33A cells at $48 \mathrm{~h}$ (Figure 6). Binase treatment did not alter p53 levels in C33A cells while IFN $\alpha 2 b$ increased p53 levels (Figure 7). Moreover, treatment with either binase or a combination of binase and IFN $\alpha 2 b$ did not alter pRb levels in C33A cells (Figure 7).

\section{DISCUSSION}

Vaccination remains the most effective treatment against HPV by protecting individuals against contracting the virus and preventing its manifestation as warts, cervical ectoption and the prospective development of

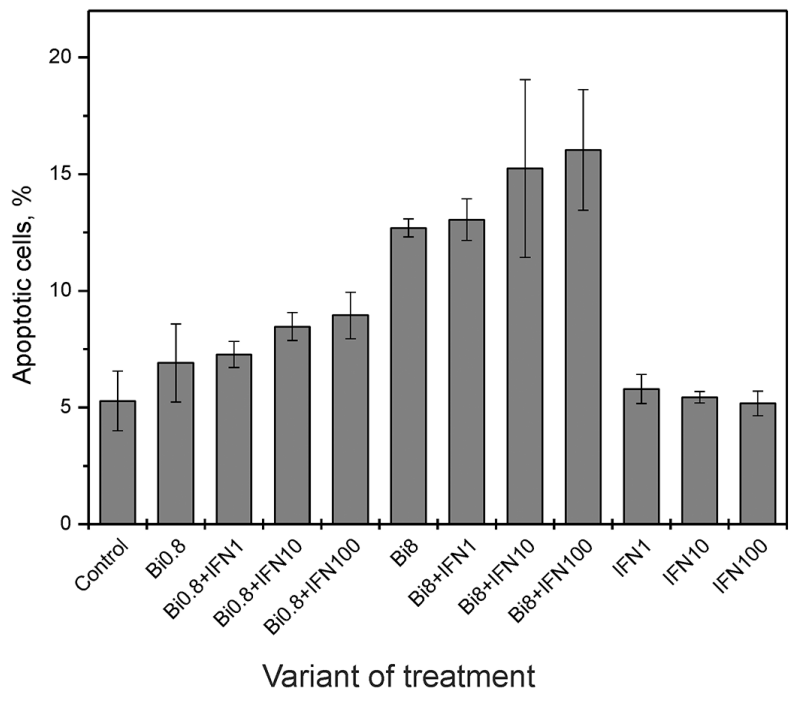

Figure 6: Effect of combined binase and INF $\alpha 2 b$ treatment on $\mathrm{C} 33 \mathrm{~A}$ cell death. Flow cytometry analysis of percent apoptosis in HPV-negative C33A cells treated with 0.8 and $8 \mu \mathrm{M}$ binase with or without 1,10 and $100 \mathrm{ng} / \mathrm{ml}$ INF $\alpha 2 \mathrm{~b}$ (INF) at $48 \mathrm{~h}$. Each value represents the mean $\pm \mathrm{SD}$ of at least three independent experiments performed in triplicate.
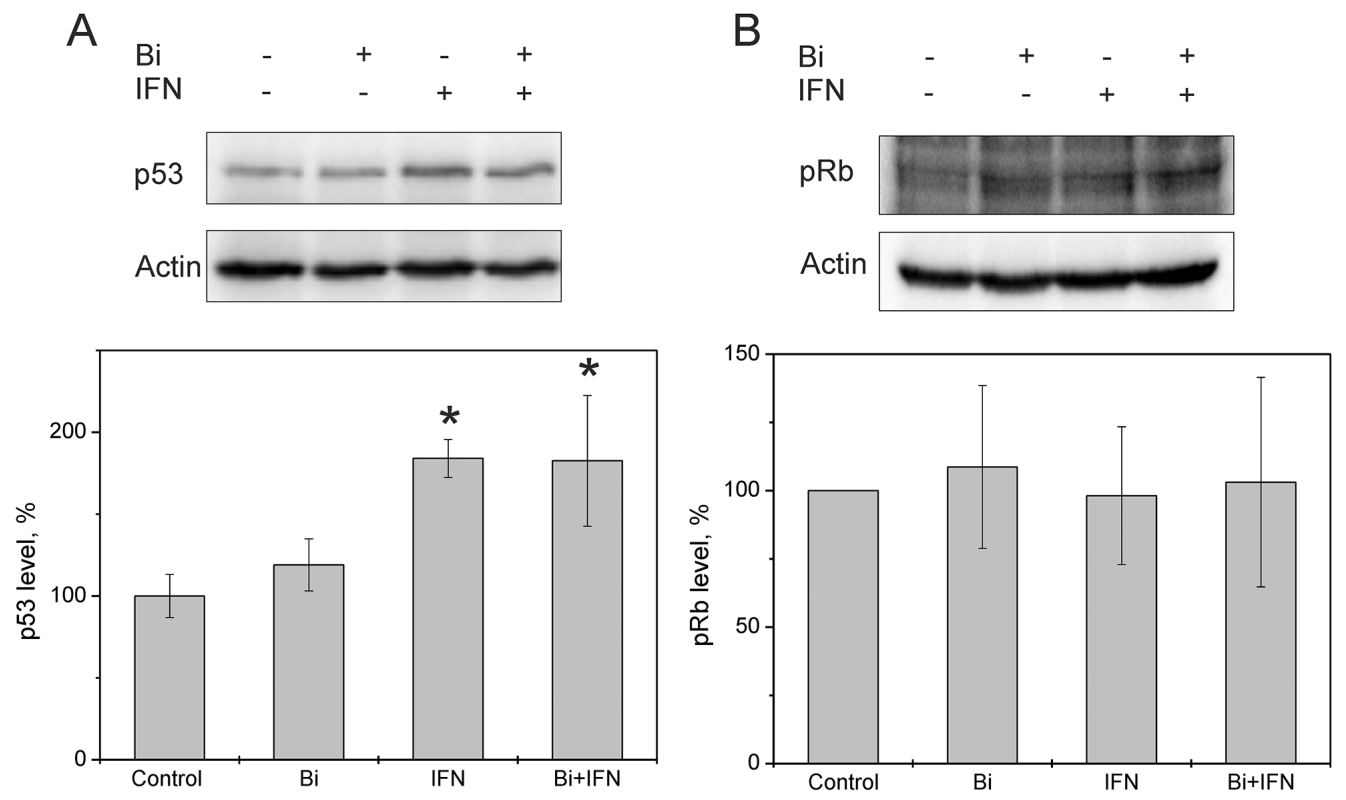

Figure 7: Effect of combined binase and INF $\alpha 2 b$ treatment on p53 and pRb levels in C33A cells. Representative western blot and bar graph showing levels of (A) p53 and (B) pRb in C33A cells treated with $8 \mu \mathrm{M}$ binase, with or without $100 \mathrm{ng} / \mathrm{ml} \mathrm{INF} \alpha 2 \mathrm{~b}$ for $48 \mathrm{~h}$, relative to untreated control cells. Each value represents mean \pm SD of three independent experiments. Note: $*$ denotes $\mathrm{p}<0.05$. 
HPV-associated cancers [1]. However, vaccination is ineffective in HPV infected individuals. In addition, vaccination of the large world population, especially third world countries where HPV-infection is most widespread is challenging. There are no effective means to eliminate HPV from infected individuals and prevent the development of the associated diseases [21]. Current treatment of HPV infections relies mostly on removal of warts and HPV-infected lesions through various ablative and non-surgical therapies. Prospective vaccines based on patient-derived dendritic cells are very expensive, logistically problematic and need to be tailored individually for each patient. Hence, there is a high demand for new, effective, comprehensive and inexpensive preventive and therapeutic avenues against HPV-associated diseases.

Binase is selectively toxic for many cancer cells and inhibits tumor growth and metastasis in animal models [10, 17]. It does not affect normal cells or induce specific T-cell immune responses, but has hepatoprotective properties [18, 22]. Furthermore, binase demonstrates antiviral activities against rabies, influenza and other viruses [11, 19]. We demonstrated that the combined anticancer and antiviral activities of binase are responsible for its selective toxicity against HPV-positive cervical carcinoma SiHa cells, but not against HPV-negative C33A cells (Figures 1, 2 and 6). The efficiency of binase antitumor activity depends on the expression of specific oncogenes, which are downregulated by binase treatment [14]. The malignant transformation state of SiHa cells is maintained by the expression of the high-risk HPV-16 encoded E6 and E7 proteins [23]. In the present study, we demonstrated that binase treatment of $\mathrm{SiHa}$ cells resulted in substantial downregulation of the viral E6 and E7 proteins (Figure 3) and increased the levels of tumor suppressor proteins, p53 and pRb, thereby inducing apoptosis and eliminating the infected cells (Figures 2, 4, and 5). The HPV-negative C33A cells that do not express E6 and E7 viral proteins were less sensitive to binase and therefore did not upregulate $\mathrm{p} 53$ and $\mathrm{pRb}$ following binase treatment. This suggests that the effect of binase on p53 and $\mathrm{pRb}$ proteins in $\mathrm{SiHa}$ cells is due to downregulation of the HPV proteins, E6 and E7.

In addition to altering expression and function of tumor suppressor proteins, the viral E6 and E7 proteins alter the innate immune response by suppressing type I IFN signaling [6]. The expression of viral oncogenes, particularly E7, is significantly higher in patients that are unresponsive to the IFN treatment than in responsive patients [24]. This suggests that downregulation of E6 and E7 by binase releases the suppression of the IFN pathway, thereby restoring the IFN response. Hence, $\mathrm{SiHa}$ cells that show low sensitivity to IFN $\alpha 2 b$ are substantially sensitized by the combined treatment with IFN $\alpha 2 b$ and binase (Figures 2, 4, and 5). The HPV-negative C33A cells treated with a combination of IFN $\alpha 2 \mathrm{~b}$ and binase show similar sensitivity to $\mathrm{C} 33 \mathrm{~A}$ cells treated with binase only (Figure 6).

Figure 8 shows the probable mechanism by which binase suppresses E6 and E7 viral oncogenes in HPVpositive cells. E6 and E7 proteins suppress interferon response and tumor suppressor proteins, p53 and pRb, thereby enhancing cell survival. Binase treatment decreases E6 and E7 levels probably by inhibiting viral replication and E6/E7 expression. This results in restoring IFN signaling and restoration of the $\mathrm{p} 53$ and $\mathrm{pRb}$, thereby inducing cell death.

In conclusion, we demonstrated that binase treatment decreases E6 and E7 viral proteins in HPV-16 positive SiHa cells. This results in higher p53 and pRb tumor suppressor protein levels and restores IFN signaling
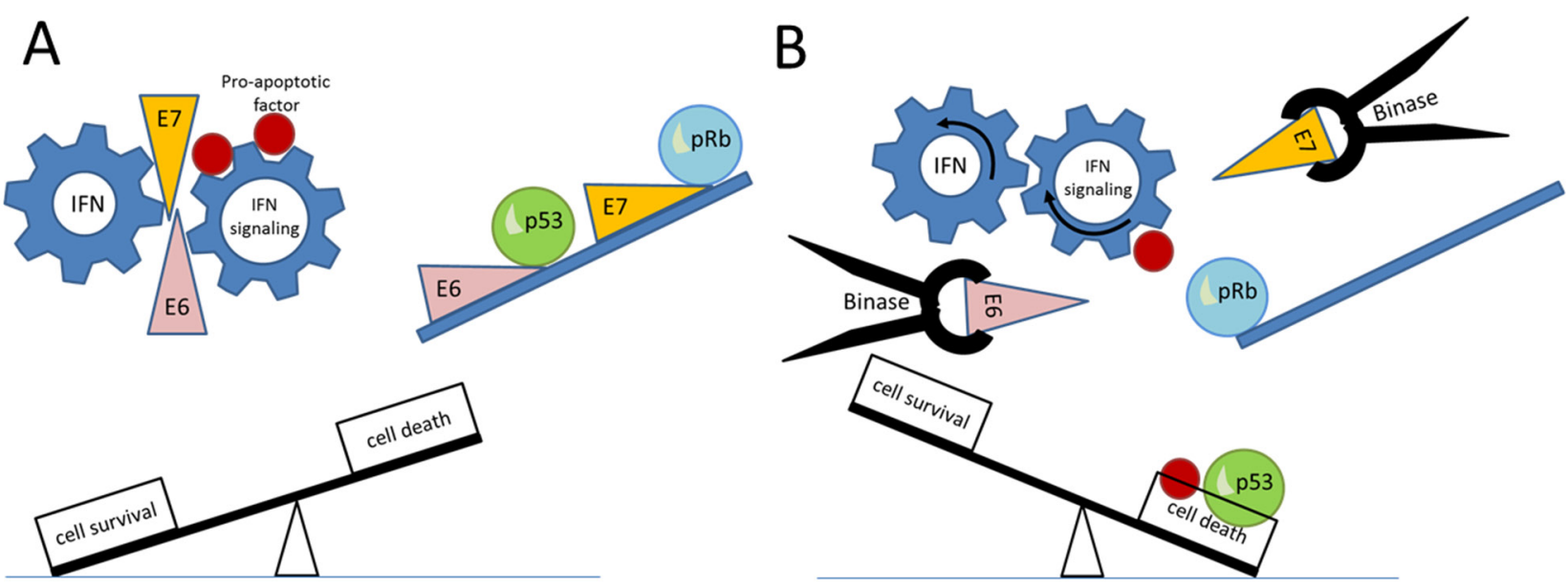

Figure 8: Schematic representation of the effect of binase on HPV-positive cervical carcinoma cells expressing E6 and E7 viral oncogenes. (A) E6 and E7 proteins are shown as pink and orange wedges, which suppress interferon response as well as tumor suppressor proteins, p53 and pRb (green and blue balls). (B) Treatment with binase (black tongs) decreases E6 and E7 levels, thereby restoring INF response and p53 and pRb levels, which induce cancer cell death. 
(Figure 8). Therefore, the combined use of binase and IFN would not only effectively eradicate HPV-positive cervical cancer cells, but also prevent malignancy due to HPV-related lesions such as genital warts, cervical intraepithelial neoplasia, as well as post-surgical reinfection with high risk HPVs.

\section{MATERIALS AND METHODS}

\section{Binase enzyme preparation and purification}

The purified $12.3 \mathrm{kDa}$ Binase enzyme was prepared from Escherichia coli BL21(DE3) with pGEMEX1/ent/ binase plasmid as described previously $[25,26]$. Endotoxin contamination in binase preparations was determined by the Limulus amoebocyte lysate test (LAL; Charles River Endosafe) and was less than $5 \mathrm{EU} / \mathrm{mg}$. Binase activity was determined using poly(I) as substrate as described previously [27].

\section{Cell culture}

SiHa and C33A epithelial cell lines were obtained from the American Type Culture Collection (ATCC, Manassas, Virginia, USA). The SiHa and C33A cells were grown in RPMI-1640 and DMEM media, respectively, supplemented with 10\% FBS, 2mM L-glutamine, 100 units $/ \mathrm{mL}$ penicillin and $100 \mathrm{mg} / \mathrm{mL}$ streptomycin at $37^{\circ} \mathrm{C}$ in a humid atmosphere with $5 \% \mathrm{CO}_{2}$.

\section{IFNa2b gene cloning and plasmid construction}

The IFN $\alpha 2 b$ gene was assembled from several chemically synthesized overlapping oligonucleotides by PCR. Its nucleotide sequence was optimized based on codon usage in highly expressed $E$. coli genes. The $I F N \alpha 2 b$ gene was fused to 3 '-terminus of the SUMO [28] gene by overlapping PCR with the intermediate amino acid sequence at the junction to generate a fusion protein,(SUMO)-QIGG-(IFN $\alpha 2 b)$-CDLP. The 5'-terminus of SUMO gene was extended by the amino acid sequence, GHHHHHHGS. The hybrid SUMO-IFN $22 b$ gene was cloned into pET39b plasmid vector between restriction sites, NdeI and HindIII.

\section{IFN $\alpha 2 b$ isolation and purification}

The SUMO-IFN $\alpha 2 \mathrm{~b}$ gene was expressed in the E. coli strain BL21 (DE3). The BL21 (DE3) cells were grown overnight in the ZYM-5052 autoinduction medium containing $200 \mu \mathrm{g} / \mathrm{ml}$ Kanamycin [29]. Then, the cells were harvested and disrupted by sonication. The insoluble fraction was pelleted at $50,000 \mathrm{xg}$ for $30 \mathrm{~min}$ at $4^{\circ} \mathrm{C}$, and the supernatant was loaded onto a $1 \mathrm{ml}$ HisTrap HP column (GE Healthcare). After washing, the bound proteins were eluted with a linear gradient of $30-500 \mu \mathrm{M}$ imidazole. The fractions containing SUMO-IFN $\alpha 2 \mathrm{~b}$ were pooled and digested at $6^{\circ} \mathrm{C}$ overnight with SUMO hydrolase (ULP1) in a1:200 molar ratio (enzyme:substrate). Then, the protein solution was desalted and concentrated with Amicon Ultra-15 centrifugal filter and reapplied to a $1 \mathrm{ml}$ HisTrap HP column (GE Healthcare). The flow through was collected and loaded onto Mono Q 5/50 GL column. The bound protein was eluted with a linear $0-1 \mathrm{M} \mathrm{NaCl}$ gradient. The fractions were analyzed by $15 \%$ reduced SDS-PAGE. The fractions containing IFNa2b were pooled and concentrated with Amicon Ultra-15 centrifugal filter and then sterile filtered through a $0.22 \mu \mathrm{m}$ membrane filter. Endotoxin levels in IFN $\alpha 2$ b preparation determined by the Limulus amoebocyte lysate test (LAL; Charles River Endosafe) and were less than $100 \mathrm{EU} / \mathrm{mg}$. The activity determined by the viral resistance test was not less than $2 \times 10^{8} \mathrm{IU} / \mathrm{mg}$ and the purity was $\geq 97 \%$ as determined by HPLC (See Supplementary Figure 2).

\section{Real time cell index analysis}

Real time cell index analysis was performed to measure focal adhesion of live cells using xCELLigence real time cell analyser (RTCA; ACEA Biosciences) [30]. The xCELLigence biosensor measured cellular adhesion and the cell index (unitless) was determined by the xCELLigence software (version 1.2.1). Cells were seeded onto custom RTCA E16 plates (ACEA Biosciences), coated with high-density gold arrays for measuring electric impedance. The cells were incubated for $24 \mathrm{~h}$ to attain a stable cell index followed by treatment with binase or combination of binase and IFN $\alpha 2 b$. Cell index measurements were recorded every 15 min during the course of cell proliferation.

\section{WST-1 cell viability assay}

Cell viability was assessed with a WST-1 test kit (Roche Diagnostics), which is based on the cleavage of water-soluble tetrazolium salt by mitochondrial dehydrogenases in live cells. SiHa cells were seeded in 96-well plates and cultured for $24 \mathrm{~h}$ at $37^{\circ} \mathrm{C}$. Then, the cells were treated with binase and/or IFN $\alpha 2$ b for $48-72$ $\mathrm{h}$ followed by incubation with WST-1 reagent for $60 \mathrm{~min}$ at $37^{\circ} \mathrm{C}$. The absorbance of samples was measured in a multiscan FC microplate reader (Thermo Fisher Scientific) at $450 \mathrm{~nm}$. A mixture of cell-free medium with the WST-1 reagent was used as a background control. The activity of mitochondrial dehydrogenases was calculated as the difference in absorbance between each sample and the background control. Respiratory activity of untreated cells was taken as $100 \%$. The experiment was performed in triplicate and reported as mean $\pm \mathrm{SD}$.

\section{Flow cytometry analysis of apoptosis}

We performed flow cytometry analysis to determine the percent apoptosis/necrosis by double staining with Pacific Blue conjugated Annexin-V (Molecular Probes) and 
propidium iodide (PI; Sigma). The cells were first washed with PBS at $4^{\circ} \mathrm{C}$ and resuspended in $0.1 \mathrm{ml}\left(1 \times 10^{6}\right.$ cells/ $\mathrm{ml}$ ) of buffer-A (10 mM Hepes, $140 \mathrm{mM} \mathrm{NaCl}, 2.5 \mathrm{mM}$ $\mathrm{CaCl}_{2}, \mathrm{pH}$ 7.4). Then, they were incubated with $5 \mu \mathrm{l}$ of Pacific Blue-conjugated Annexin V (Ex/Em 405/455 nm) for $15 \mathrm{~min}$ at room temperature in darkness. Then, $400 \mu \mathrm{l}$ of buffer-A was added and incubated with $10 \mu \mathrm{g} / \mathrm{ml} \mathrm{PI} \mathrm{(Ex/Em}$ $493 / 632 \mathrm{~nm}$ ) for 1-2 min before analysis in a GALLIOS flow cytometer (Beckman Coulter). The typical forward and side scatter plot showing distribution of SiHa and C33a cells by size and granularity is shown in the Supplementary Figure 3A, 3B. In our analysis, we excluded cell debris lying outside the R1 gate (Supplementary Figure 3). We analyzed atleast 10000 cells for each sample by Annexin-V Pacific Blue (FL9) versus propidium iodide (FL4) (Supplementary Figure 3B). The Annexin- $\mathrm{V}^{+} \mathrm{PI}^{-}$cells were considered apoptotic (lower right quadrant), Annexin- $\mathrm{V}^{-} \mathrm{PI}^{+}$(upper left quadrant) were considered as necrotic cells, while all Annexin- $\mathrm{V}^{+} \mathrm{PI}^{+}$(upper right quadrant), Annexin- $\mathrm{V}^{+} \mathrm{PI}$ (lower right quadrant) and Annexin- $\mathrm{V}^{-} \mathrm{PI}^{+}$were considered as dying cells (Supplementary Figure 3B). The apoptotic and dying cells were expressed as a percentage of the total number of cells. The experiments were repeated thrice and were expressed as mean $\pm \mathrm{SD}$.

\section{Western blotting}

The harvested cells were washed with ice-cold PBS and solubilized in ice-cold lysis buffer $(25 \mathrm{mM}$ Tris- $\mathrm{HCl}$, $\mathrm{pH}$ 7.6, $150 \mathrm{mM} \mathrm{NaCl}, 1 \%$ Nonidet-P40, 0.1\% SDS, 1\% sodium deoxycholate, $1 \mu \mathrm{M}$ of PMSF) with constant stirring at $4{ }^{\circ} \mathrm{C}$ for $1 \mathrm{~h}$. The cell lysates were centrifuged at $13000 \mathrm{xg}$ for $10 \mathrm{~min}$ and the protein supernatants were collected and quantified. Equal amounts of protein lysates were separated on SDS-PAGE and transferred onto PVDF membranes. The membranes with separated proteins were blocked with 5\% skimmed milk in 1X PBST for $1 \mathrm{~h}$. Then, the membranes were incubated overnight at $4^{\circ} \mathrm{C}$ with the following primary antibodies: HPV16 E6 (ab70, dilution 1:500) and HPV16 E7 (ab30731, dilution 1:1000) from Abcam; p53 (sc-126, dilution 1:1000) from Santa Cruz Biotechnology; pRb (9309s, dilution 1:2000) from Cell Signaling; $\beta$-actin (AM4302, dilution 1:15000) from Ambion. Then, the blots were incubated with the appropriate horseradish peroxidaseconjugated secondary antibodies and developed by the enhanced chemiluminescence SuperSignal ${ }^{\mathrm{TM}}$ West Femto Maximum Sensitivity Substrate kit (Thermo Scientific). Chemiluminescence was detected using Bio-Rad ChemiDoc MP instrument and the protein bands were analyzed by densitometry using the Image Lab program (Bio-Rad).

\section{Statistical analysis}

The data are shown as mean \pm standard deviation measure from triplicate values obtained from 3 independent experiments. The differences among the groups were analyzed by Student's t-test and $p<0.05$ was considered statistically significant. Statistica 7 software was used for analysis.

\section{Abbreviations}

HPV, human papilloma virus; $p R b$, retinoblastoma protein; IFN, interferon; RNases, ribonucleases.

\section{Author contributions}

VAM and IYuP conceived the project and drafted the paper with contributions from KMB, AAA, PMC and AAM. KMB, IYuP and AAS performed the experiments; PMC and AAM coordinated the study and contributed materials and reagents.

\section{CONFLICTS OF INTEREST}

The authors declare no conflicts of interest.

\section{FUNDING}

The study was supported by the Russian Science Foundation grant no. 14-50-00060.

\section{REFERENCES}

1. Park IU, Introcaso C, Dunne EF. Human papillomavirus and genital warts: a review of the evidence for the 2015 centers for disease control and prevention sexually transmitted diseases treatment guidelines. Clin Infect Dis. 2015; 61:S849-855.

2. Winer RL, Hughes JP, Feng Q, O'Reilly S, Kiviat NB, Holmes KK, Koutsky LA. Condom use and the risk of genital human papillomavirus infection in young women. N Engl J Med. 2006; 354:2645-2654.

3. Bernardi MP, Ngan SY, Michael M, Lynch AC, Heriot AG, Ramsay RG, Phillips WA. Molecular biology of anal squamous cell carcinoma: implications for future research and clinical intervention. Lancet Oncol. 2015; 16:e611-621.

4. Chaturvedi AK, Engels EA, Pfeiffer RM, Hernandez BY, Xiao W, Kim E, Jiang B, Goodman MT, Sibug-Saber M, Cozen W, Liu L, Lynch CF, Wentzensen N, et al. Human papillomavirus and rising oropharyngeal cancer incidence in the United States. J Clin Oncol. 2011; 29:4294-4301.

5. zur Hausen H. Papillomaviruses and cancer: from basic studies to clinical application. Nat Rev Cancer. 2002; 2:342-350.

6. Koromilas AE, Li S, Matlashewski G. Control of interferon signaling in human papillomavirus infection. Cytokine Growth Factor Rev. 2001; 12:157-170.

7. Beglin M, Melar-New M, Laimins L. Human papillomaviruses and the interferon response. J Interferon Cytokine Res. 2009; 29:629-635. 
8. Il'inskaia ON, Makarov AA. Why ribonucleases cause death of cancer cells. Mol Biol (Mosk). 2005; 39:3-13.

9. Fang EF, Ng TB. Ribonucleases of different origins with a wide spectrum of medicinal applications. Biochim Biophys Acta. 2011; 1815:65-74.

10. Mitkevich VA, Makarov AA, Ilinskaya ON. Cell targets of antitumor ribonucleases. Mol Biol (Mosk). 2014; 48:181-188.

11. Ilinskaia ON, Shah Makhmud R. Ribonucleases as antiviral agents. Mol Biol (Mosk). 2014; 48:615-623.

12. Mitkevich VA, Kretova OV, Petrushanko IY, Burnysheva KM, Sosin DV, Simonenko OV, Ilinskaya ON, Tchurikov NA, Makarov AA. Ribonuclease binase apoptotic signature in leukemic Kasumi-1 cells. Biochimie. 2013; 95:1344-1349.

13. Makarov AA, Kolchinsky A, Ilinskaya ON. Binase and other microbial RNases as potential anticancer agents. Bioessays. 2008; 30:781-790.

14. Mitkevich VA, Petrushanko IY, Spirin PV, Fedorova TV, Kretova OV, Tchurikov NA, Prassolov VS, Ilinskaya ON, Makarov AA. Sensitivity of acute myeloid leukemia Kasumi-1 cells to binase toxic action depends on the expression of KIT and AML1-ETO oncogenes. Cell Cycle. 2011; 10:4090-4097.

15. Mitkevich VA, Orlova NN, Petrushanko IY, Simonenko OV, Spirin PV, Prokofieva MM, Gornostaeva AS, Stocking C, Makarov AA, Prassolov VS. [Expression of FLT3-ITD oncogene confers mice progenitor B-cells BAF3 sensitivity to the ribonuclease binase cytotoxic action]. [Article in Russian]. Mol Biol (Mosk). 2013; 47:282-285.

16. Ilinskaya O, Decker K, Koschinski A, Dreyer F, Repp H. Bacillus intermedius ribonuclease as inhibitor of cell proliferation and membrane current. Toxicology. 2001; 156:101-107.

17. Mironova NL, Petrushanko IY, Patutina OA, Sen'kova AV, Simonenko OV, Mitkevich VA, Markov OV, Zenkova MA, Makarov AA. Ribonuclease binase inhibits primary tumor growth and metastases via apoptosis induction in tumor cells. Cell Cycle. 2013; 12:2120-2131.

18. Sen'kova AV, Mironova NL, Patutina OA, Mitkevich VA, Markov OV, Petrushanko IY, Burnysheva KM, Zenkova MA, Makarov AA. Ribonuclease binase decreases destructive changes of the liver and restores its regeneration potential in mouse lung carcinoma model. Biochimie. 2014; 101:256-259.

19. Shah Mahmud R, Ilinskaya ON. Antiviral activity of binase against the pandemic influenza A (H1N1) virus. Acta Naturae. 2013; 5:44-51.
20. Koromilas AE, Li S, Matlashewski G. Control of interferon signaling in human papillomavirus infection. Cytokine Growth Factor Rev. 2001; 12:157-170.

21. Rosales R, Rosales C. Immune therapy for human papillomaviruses-related cancers. World J Clin Oncol. 2014; 5:1002-1019.

22. Ilinskaya ON, Zelenikhin PV, Petrushanko IY, Mitkevich VA, Prassolov VS, Makarov AA. Binase induces apoptosis of transformed myeloid cells and does not induce T-cell immune response. Biochem Biophys Res Commun. 2007; 361:1000-1005.

23. Xue X, Wang B, Du W, Zhang C, Song Y, Cai Y, Cen D, Wang L, Xiong Y, Jiang P, Zhu S, Zhao KN, Zhang L. Generation of affibody molecules specific for HPV16 E7 recognition. Oncotarget. 2016; 7:73995-74005. https://doi. org/10.18632/oncotarget.12174.

24. Arany I, Nagamani K, Tyring SK. Interferon resistance is independent from copy numbers in benign HPV-induced lesions. Anticancer Res. 1995; 15:1003-1006.

25. Schulga A, Kurbanov F, Kirpichnikov M, Protasevich I, Lobachev V, Ranjbar B, Chekhov V, Polyakov K, Engelborghs Y, Makarov A. Comparative study of binase and barnase: experience in chimeric ribonucleases. Protein Eng. 1998; 11:775-782.

26. Makarov AA, Protasevich II, Kuznetsova NV, Fedorov BB, Korolev SV, Struminskaya NK, Bashulina NP, Leschinskaya IB, Hartley RW, Yakovlev GI, Esipova NG. Comparative study of thermostability and structure of close homogenes - Barnase and Binase. J Biomol Struct Dyn. 1993; 10:1047-1065.

27. Mitkevich VA, Tchurikov NA, Zelenikhin PV, Petrushanko IY, Makarov AA, Ilinskaya ON. Binase cleaves cellular noncoding RNAs and affects coding mRNAs. FEBS J. 2010; 277:186-196.

28. Malakhov MP, Mattern MR, Malakhova OA, Drinker M, Weeks SD, Butt TR. SUMO fusions and SUMO-specific protease for efficient expression and purification of proteins. J Struct Funct Genomics. 2004; 5:75-86.

29. Studier FW. Protein production by auto-induction in high density shaking cultures. Protein Expr Purif. 2005; 41:207-234.

30. Wiltshire R, Nelson V, Kho DT, Angel CE, O'Carroll SJ, Graham ES. Regulation of human cerebro-microvascular endothelial baso-lateral adhesion and barrier function by S1P through dual involvement of S1P1 and S1P2 receptors. Sci Rep. 2016; 6:19814. 